\title{
New shield could offer better protection during dental surgery
}

Dental patients and practitioners could be better protected from COVID-19 and other airborne viruses and bacteria thanks to the development of a new environmentally friendly shield by a multidisciplinary team from the University of Bristol and University Hospitals Bristol and Weston NHS Foundation Trust (UHBW). The shield could also increase the number of patients seen by dentists and help reduce procedure wait times.

The device, called NoPaS (Novel Patient Shield), is designed to protect patients and practitioners from harmful diseases including COVID-19, which can be spread through aerosols generated during dental procedures.
The device could also significantly cut clinical waste, including the use of disposable personal protective equipment (PPE).

Dr Mojtaba Dorri, Consultant in Restorative Dentistry in the UHBW, who led the development of NoPaS, said: 'During the COVID-19 pandemic the development of innovative environmentally friendly solutions has been much needed to allow routine dental care to be delivered in a safe environment without risking virus transmission. With the virus still circulating and the chance of future pandemics, it is important routine dental care continues to ensure public oral health is not affected.

'With minor modification, NoPaS can be

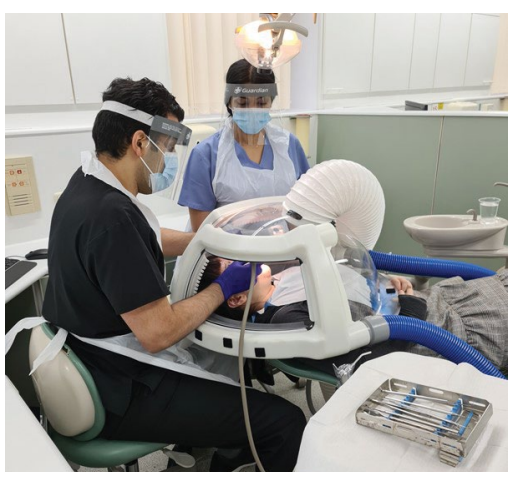

used for medical procedures on the head and neck, including endoscopy, anaesthetics and ear, nose and throat.

'Thanks to the Elizabeth Blackwell Institute, MRC Confidence in Concept and Bristol and Weston Hospitals Charity (formerly Above \& Beyond) grants, our NoPaS prototype has been fully tested. With the device now patented, we are actively seeking partnerships to take NoPaS into mass production.'

\section{CONFERENCE REPORT}

\section{BARDES coming of age?}

By Dr R. McAndrew on behalf of Professor Janice Ellis, Professor Barry Quinn, Dr Vivian Binnie, Dr Alison Cairns,

Dr Claudia Cunningham, Dr Zoe Freeman, Dr Melanie Nasseripour and Dr Kim Piper

The 4th meeting of the British Alliance for Researchers in Dental Education and Scholarship (BARDES) was held in October of 2021. Nearly 100 attendees from the UK and beyond attended an online conference hosted by University of Glasgow Dental School.

A highly informative day delivered two excellent keynote lectures: one from Grant Creaney entitled 'Sustainability: what should we be teaching the students?' and the other from Al Ross on 'Incorporating human factors and non-technical skills into the undergraduate dental curriculum'. Additionally, three $\mathrm{PhD}$ presentations were warmly received from Dr Jamie Dickie - 'Building validity evidence for longitudinal assessment of dental students', Dr Claudia Cunningham - 'Selection to undergraduate dental education' and $\mathrm{Mr}$ Rayan Sharka - 'Perceived risk factors of using digital and social media in the general and dental professional contexts. Further short research presentations were delivered by Ms Faith Campbell on 'Co-creation of a comprehensive intervention to facilitate deep reflection for undergraduate dental students', and a joint presentation was delivered by Professor Albert Leung and Dr Peter Fine, outlining the findings of an Association for Dental Education in Europe (ADEE)-backed survey on the influence of COVID-19 on feedback.

Attendee interaction and participation was key to the whole day with attendees exploring the topic 'Working collaboratively with other Dental Schools' in workshops hosted by representatives from BARDES. The workshops proved particularly useful and provided much discussion.

The group continues to go from strength to strength with an overriding wave of support to formalise the group's existence. A small working party has been organised under the guidance of Professor Janice Ellis to explore the establishing of a bona fide 'Society' and work has already begun with the establishment of the mission statement: 'To connect and support dental education researchers and scholars to deliver an evidence base that informs the future delivery of exceptional dental education' and efforts to establish a web presence etc.

The Alliance endeavours to promote research into dental education and scholarship through its articles and its commitment to:
- Facilitate connectivity of providers of undergraduate and postgraduate dental education programmes to enable and enhance delivery of educational research

- Develop communities of practice with similar areas of interest and expertise

- Provide opportunity for networking through its activities, conferences and web presence

- Provide support for members of the Alliance in the form of access to expertise, mentorship and academic resources

- Support the delivery of research projects by connecting researchers to relevant colleagues with a specific skill set and through the award of funding/grants

- Support the growth development of early-career colleagues and the discipline of dental education research.

Professor Barry Quinn, Chair of Restorative Dentistry and Dental Education, has kindly accepted to host the next conference of BARDES at the University of Liverpool, School of Dentistry in the autumn of 2022 . 